\title{
Use of Social Networking Sites among University Students in Ajman, United
}

\section{Arab Emirates}

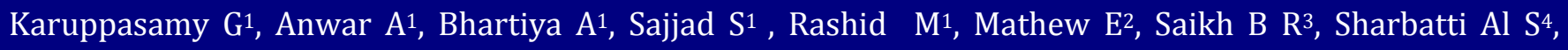
Sreedharan $\mathrm{J}^{5}$

14th Year MBBS students, College of Medicine, Gulf Medical University, Ajman, UAE

${ }^{2}$ Professor, Department of Community Medicine, Gulf Medical University, Ajman, UAE

${ }^{3}$ Professor and Head, Department of Community Medicine, Gulf Medical University, Ajman

United Arab Emirates

${ }^{4}$ Assistant Professor, Department of Community Medicine, Gulf Medical University, Ajman

United Arab Emirates

${ }^{5}$ Assistant Director, Research Division, Gulf Medical University, Ajman, UAE

\section{Chief Editor}

Dr. Indrajit Banerjee

Grammar Editor

Dr. Nishida Chandrasekharan

Original Article

\author{
Corresponding Author \\ Dr. Jayadevan Sreedharan PhD \\ Assistant Director, Research division \\ Gulf Medical University \\ Ajman, UAE \\ Tel: +971 67463333 \\ Fax: +97167464222 \\ Email: researchdivision@gmu.ac.ae
}

\section{Abstract}

\section{Background}

Social networking sites are web-based services through which individuals can create a public or semi-public profile within a bounded system, connect with a list of other linked users, and view and interact with a list of their connections and with those made by others within the system. To estimate the proportion of university students using social networking sites (SNS) and to determine the association between SNS use and age, gender, nationality, course and year of study, living context, family size, number of close friends, close relationships, stress related to studies and interpersonal relationships.

\section{Materials and Methods}

A cross sectional study was carried out among 300 students from two universities in Ajman, UAE. A self-administered, content-validated and pilot-tested questionnaire was used. The participants answered questions related to their use of social networking sites and details of socio-demographic variables. The data collected were entered into Microsoft Excel and transferred to PASW 18.0 version. Data were analyzed as frequencies, percentages, means and SDs, and Chi-square test used for associations. The odd ratio was 
calculated for the significant variables to find the degree of association. The SNS usage was categorized as average, moderate or high based on mean and SD on the SNS test score.

\section{Results}

The study population was comprised of $41.6 \%$ males and $58.3 \%$ females. $89 \%$ used social networking sites (SNS) and $11 \%$ were non-users. Of the 267 users of SNS, $58.8 \%$ were average users, $37.8 \%$ moderate users and $3.4 \%$ high users. Students in the first and second years of study, small family size, age below 20 years, male gender, being in a nonmedical study program, friends in close relationship were found to be associated with higher SNS use.

\section{Conclusion}

Social networking sites were found to be popular among a large number of university students in the UAE, this being more so among males and non-medical students of first two years of study.

Keywords: Social Networking Sites, university students, UAE

\section{Introduction}

Social networking sites are web-based services through which individuals can create a public or semi-public profile within a bounded system, connect with a list of other linked users, and view and interact with a list of their connections and with those made by others within the system ${ }^{1}$. Popular sites include Facebook, MySpace, Twitter, Orkut, Flickr, Friendster and Orkut. These sites can have content related to the work environment, play a role in romantic relationships and courting, connect those with shared interests such as music or politics, or bring together the college student population ${ }^{2}$. They allow users to display their personal information, communicate with one another, post pictures or videos, view other users' profiles, play games and even organize events. With the release of enhanced and newer technology, and widespread access to the internet, social networking has become an easier task.

Like every good thing in life, indulgence and excessive use can lead to problems. It is estimated that approximately nine million Americans can be labeled as pathological computer users addicted to the internet ${ }^{3}$. It has even been suggested, addictive Internet use can be considered as an impulse-control disorder that does not involve an intoxicant ${ }^{4}$, or classified under a larger subset of behavioral disorders ${ }^{5}$.

Studies world over have examined different aspects of internet use and its psychological effects. A study done among adolescents in China found that $10.2 \%$ were moderately and $1.06 \%$ severely addicted to the internet ${ }^{6}$. Another study in China found that $98 \%$ of the teenage population used Instant Messenger services, with an addiction rate of $10 \%{ }^{7}$. A Taiwanese report found positive results with regard to addiction to online gaming ${ }^{8}$.

It being establishment that internet and its related features like gaming and networking are viable modalities for addiction, the question arises whether people are addicted to social networking sites. The other question that surfaces is which population subset is at most risk. Kendell's report found that the teenage student population is at risk of developing pathological internet usage, and related it to the ease of accessibility to the internet ${ }^{9}$.

Unlike the studies done for addiction to online gaming and pathological internet usage, studies for social networking have focused on topics such as relationship to substitution of interaction ${ }^{10}$ and the effect on self image and self esteem $^{11}$. No studies were found on the extent of social networking site addiction among university students. Moreover it is important to identify the risk groups and the need for guidance, at which point the necessary preventive action can be undertaken to avoid negative psychosocial, health and educational effects upon them.

The present research assessed the frequency of usage and levels of addiction, and explored any association between socio-demographic factors and SNS use among university students, the promise of future productivity.

\section{Material and Methods}

\section{Study design and the participants}

A cross sectional survey was carried out with 300 students from one medical university and one non-medical university in Ajman, UAE. Students from the two universities willing to participate formed the study group and were selected by non-probability convenience sampling, after obtaining permission for the survey.

\section{Data collection}

The study was conducted over a period of 10 months, from 5th July 2010 to 12th May 2011. Data collection was done in March and April, 2011. A self-administered questionnaire that had questions of both open-ended and close-ended formats was used to collect data on the students' sociodemographic background and their use of social networking sites, and internet use. In addition, a set of 20 questions, prepared using Internet Addiction Test (IAT) with the reference changed to 'social networking sites', assessed the students' addiction to SNS. The users rated their experiences and the problems of using the SNS on a Likert scale as 5-Always; 4-Often; 3-Frequently 2-Occasionally; 1Rarely; and 0-Not applicable. Total scores ranged from 20 to 100. A score 20-49 was taken as average usage, 50-79 moderate problematic use; $80-100$ as severe use. A pilot study among 10 students to ensure clarity of questions and resolve ambiguities led to a few minor changes.

The researchers approached the students at each university campus on weekdays during working hours. The purpose and reason for the study was explained to the students. The participants were assured anonymity and confidentiality. The questionnaires were distributed to those who gave a verbal consent for participation and collected immediately after completion, till the required number was achieved. 


\section{Inclusion criteria}

All students of any Gender, Age and Nationality, willing to participate from the respective Universities were included in the study.

\section{Exclusion criteria}

Any student who was absent at the time of data collection, not willing to participate, or who gave incomplete survey form did not enter the study.

\section{Sample size calculation}

Considering a reported problematic internet use of $34 \%{ }^{12}$ prevalence of problematic SNS use was assumed to be roughly $25 \%$. For $95 \%$ confidence interval and significance level $\alpha=5 \%$, required sample size was $300^{13}$.

\section{Outcome Variables}

Level of addiction to social networking sites was the outcome variable under consideration in the study.

\section{Explanatory variables}

Basic demographic factors, socio-demographic factors and profile of use of social networking sites were the descriptive variables.

\section{Ethical committee approval}

Ethical approval was obtained from the Ethics Committee of Gulf Medical University.

\section{Data management and statistical analysis}

The collected data was coded, fed into Excel sheet, and transferred to SPSS 18.0 version. Data were grouped together for the purpose of analysis.

An SNS user was defined as anyone who had an account on a Social Networking Site, regardless of the amount of time spent on it. A Non-user was anyone who did not have an account and did not spend any time on any form of SNS.

Due to the low frequency of High Users the SNS addiction test score was grouped as Average use and Moderate to High use. The independent variables of our study were statistically analyzed with Chi square test and Logistic regression, against the SNS addiction scores, $\mathrm{P}<0.05$ is considered as statistically significant ${ }^{14}$.

\section{Results:}

Table 1 shows basic demographic distribution of users and non-users. Among those aged $<20$ years, there were 126 $(88.7 \%)$ users and among those $\geq 20$ years, there were 141 (89.2\%) users. Odds ratio is 1.94 (95\% Cl of $0.91-4.14)$. Males made up 107 (85.6\%) users and the females 160 (91.4\%). Among the South Asians 126 (91.3\%) were users, while among the Africans 43 (89.6\%) were in this category. Other categories had fewer users. There were 186 (86.9\%) users among medical students while non-medical students had $73(94.8 \%)$ users. Of the students in the junior year, 146 $(91.8 \%)$ were users and in the senior year, 104 (85.2\%) were users. The year of study (junior) was significantly associated with use of Social Networking Sites $(\mathrm{p}<0.018)$, with an Odds ratio 1.94 (95\% Cl 1.08-1.42). (Table 1 \& Table 2)

Table 1. Basic demographic distribution of users and nonusers

\begin{tabular}{|c|c|c|c|c|c|c|c|c|}
\hline \multirow{2}{*}{ Variables } & \multirow{2}{*}{ Group } & \multicolumn{2}{|c|}{ Users } & \multicolumn{2}{|c|}{ Non-users } & \multirow{2}{*}{ Total } & \multirow{2}{*}{ P value } & \multirow{2}{*}{$\begin{array}{l}\text { Odds } \\
\text { Ratio }\end{array}$} \\
\hline & & No. & $\%$ & No. & $\%$ & & & \\
\hline \multirow{2}{*}{$\begin{array}{l}\text { Age group } \\
\text { In years }\end{array}$} & $<20$ & 126 & 88.7 & 16 & 11.3 & 142 & NS & \\
\hline & $\geq 20$ & 141 & 89.2 & 17 & 10.8 & 158 & & \\
\hline \multicolumn{2}{|c|}{ Total* } & 267 & 89 & 33 & 11 & 300 & & \multirow{3}{*}{-} \\
\hline \multirow{2}{*}{ Gender } & Male & 107 & 85.6 & 18 & 14.4 & 125 & NS & \\
\hline & Female & 160 & 91.4 & 15 & 8.6 & 175 & & \\
\hline \multicolumn{2}{|c|}{ Total* } & 267 & 89 & 33 & 11 & 300 & & \\
\hline \multirow{4}{*}{$\begin{array}{c}\text { Country of } \\
\text { origin }\end{array}$} & $\begin{array}{l}\text { South } \\
\text { Asians }\end{array}$ & 126 & 91.3 & 12 & 8.7 & 138 & NS & \multirow{4}{*}{ - } \\
\hline & Arabs & 75 & 86.2 & 12 & 13.8 & 87 & & \\
\hline & Africans & 43 & 89.6 & 5 & 10.4 & 48 & & \\
\hline & Western & 20 & 83.3 & 4 & 16.7 & 24 & & \\
\hline \multicolumn{2}{|c|}{ Total* } & 264 & 88.9 & 33 & 11.1 & 297 & & \\
\hline \multirow{2}{*}{ Program } & Medical & 186 & 86.9 & 28 & 13.1 & 214 & NS & \multirow[b]{2}{*}{ - } \\
\hline & $\begin{array}{c}\text { Non- } \\
\text { medical }\end{array}$ & 73 & 94.8 & 4 & 5.2 & 77 & & \\
\hline \multicolumn{2}{|c|}{ Total* } & 259 & 89 & 32 & 11 & 291 & & \\
\hline \multirow[t]{2}{*}{ Year } & $\begin{array}{l}\text { Junior } \\
\text { years }\end{array}$ & 146 & 91.8 & 13 & 8.2 & 159 & $<0.05$ & 1.94 \\
\hline & $\begin{array}{l}\text { Senior } \\
\text { years }\end{array}$ & 104 & 85.2 & 18 & 14.8 & 122 & & 1 \\
\hline \multicolumn{2}{|c|}{ Total* } & 250 & 89 & 31 & 11 & 281 & & \\
\hline
\end{tabular}

*The varying totals are due to missing data.

Table 2 shows social factors among users and non-users. Among the students who lived with their parents 141 (87\%) were users while among those who lived with their spouse $17(94.4 \%)$ were users and 1 (5.6\%) was a non-user. Among the students who lived with a roommate 36 (92.3\%) were users and among those who lived alone 57(90.5\%) were users.

53 (19.9\%) users had few friends, 95 (35.6\%) an average number of friends and 119 (44.6\%) many friends. Among non-users, 8 (24.2\%) had few friends, 17 (51.5\%) an average number and 8 (24.2\%) many friends.

Among the users, almost equal proportions identified a family member or chose friends $(44.4 \%, 43.2 \%)$ as close relation, while 29 (12.4\%) felt close to their partner with whom they could share their joys and sorrows; among nonusers it was $46.4 \%(13), 35.7 \%$ and $17.9 \%$ respectively. 151 (56.6\%) users had a small family while 12 (36.4\%) non-users had a small family. A statistically significant association between size of family and use of Social Networking Sites was observed $(p<0.028)$. Odds ratio is $2.27(95 \% \mathrm{Cl}$ of $1.08-$ 4.81).

Students who felt stress in studies used SNS less than those without ( $87 \%$ and $93.4 \%$ respectively). The proportions of users among the students who had stress in relationships and those without were similar. Among the users 156 (58.4\%) used internet for less than 5 hours and 111 (41.6\%) 
used internet for more than 6 hours per day and among the total non users $2266.7 \%$ ) used internet for less than 5 hours and 11 (33.3\%) used it for more than 6 hours. Out of the 267 users 265 (99.3\%) used Facebook, 39 (14.6\%) Twitter, 15 (5.6\%) MySpace, 13 (4.9\%) Hi-5, 5 (2.6\%) Orkut, 7 (1.9\%) used Friendster and 14 (5.2\%) Flickr.

Table 2. Distribution of social factors among users and non-users

\begin{tabular}{|c|c|c|c|c|c|c|c|c|}
\hline \multirow[t]{2}{*}{ Variables } & \multirow[t]{2}{*}{ Group } & \multicolumn{2}{|c|}{ Users } & \multicolumn{2}{|c|}{ Non- Users } & \multirow[t]{2}{*}{ Total } & \multirow[t]{2}{*}{ P value } & \multirow{2}{*}{$\begin{array}{l}\text { Odds } \\
\text { Ratio }\end{array}$} \\
\hline & & No. & $\%$ & No. & $\%$ & & & \\
\hline \multirow{5}{*}{$\begin{array}{l}\text { Living } \\
\text { context }\end{array}$} & Parents & 141 & 87 & 21 & 13 & 162 & & \multirow[t]{5}{*}{ - } \\
\hline & Spouse & 17 & 94.4 & 1 & 5.6 & 18 & NS & \\
\hline & $\begin{array}{l}\text { Room } \\
\text { mate }\end{array}$ & 36 & 92.3 & 3 & 7.7 & 39 & & \\
\hline & Alone & 57 & 90.5 & 6 & 9.5 & 63 & & \\
\hline & Others & 13 & 86.7 & 2 & 13.3 & 15 & & \\
\hline Total* & & 264 & 88.9 & 33 & 11.1 & 297 & & \\
\hline \multirow{3}{*}{$\begin{array}{l}\text { Number } \\
\text { of close } \\
\text { friends }\end{array}$} & $<3$ & 53 & 19.9 & 8 & 24.2 & 61 & NS & \multirow[t]{3}{*}{ - } \\
\hline & $3-5$ & 95 & 35.6 & 17 & 51.5 & 112 & & \\
\hline & $>5$ & 119 & 44.6 & 8 & 24.2 & 127 & & \\
\hline Total* & & 267 & 100 & 33 & 100 & 300 & & \\
\hline \multirow{3}{*}{$\begin{array}{l}\text { Close } \\
\text { relations }\end{array}$} & Family & 104 & 44.4 & 13 & 46.4 & 117 & NS & \multirow[t]{3}{*}{ - } \\
\hline & Friends & 101 & 43.2 & 10 & 35.7 & 111 & & \\
\hline & Partner & 29 & 12.4 & 5 & 17.9 & 34 & & \\
\hline Total* & & 234 & 100 & 28 & 100 & 262 & & \\
\hline \multirow{2}{*}{$\begin{array}{l}\text { Size of } \\
\text { Family }\end{array}$} & $\leq 6$ & 151 & 56.6 & 12 & 36.4 & 163 & \multirow[t]{2}{*}{$<0.05$} & 2.27 \\
\hline & $>6$ & 116 & 43.4 & 21 & 63.6 & 137 & & 1 \\
\hline Total* & & 267 & 100 & 33 & 100 & 300 & & \\
\hline
\end{tabular}

*The varying totals are due to missing data.

Mean SNS usage in hours is $2.6 \pm 3.1$ and the mean SNS addiction test score $30.0 \pm 19.4$. Of the $<2$ hours users, 87 $(66.4 \%)$ were average users, 41 (31.3\%) moderate users and $3(2.3 \%)$ were high users. Among the 3-7 hours users 36 (52.9\%) were average users, 32 (47.1\%) moderate users and none was a high user. Among the 8 hour-users 4 (30.8\%) were average users, 7 (53.8\%) were moderate users, 2 $(15.4 \%)$ were high users $(p<0.001)$. Of the average SNS users $87(55.4 \%)$ spent <2 hours; $70(44.6 \%)>3$ hours, while 44 $(40 \%)$ of the moderate to high users spent $<2$ hours on SNS and $66(60 \%)>3$ hours.

While $64(50.8 \%)$ aged $<20$ years were average users, 62 $(49.2 \%)$ were moderate to high users. Those aged $\geq 20$ years, $93(66 \%)$ were average users and $48(34 \%)$ moderate to high users. A statistically significant association was seen between SNS addiction test score and SNS usage and age $(p<0.01)$. Odds ratio is $0.53(95 \% \mathrm{Cl}$ of $0.32-0.87)$.

Among males 49 (45.8\%) and among females 108 (67.5\%) were average users and 58 (54.2\%) and 52 (32.5\%) moderate to high users $(p<0.001)$. Odds ratio is $0.40(95 \% \mathrm{Cl}$ of $0.24-0.67$ ).

By nationality, 75 (59.9\%) were South Asians, 37 (49.3\%) Arabs, 28 (65.1\%) Africans and 14 (70\%) Westerners were average users, and 51 (40.5\%), 38 (50.7\%), 15 (34.9\%), and 6 (30\%) moderate to high users and the difference observed was not statistically significant.

Whereas 124 (66.7\%) medical and 30 (41.1\%) non-medical students were average users, 62 (33.3\%) and 43 (58.9\%) were moderate to high users with statistically significant association of $p<0.001$. Odds ratio is $2.86(95 \% \mathrm{Cl}$ of $1.64-$ 5.00).

The Chi square test showed no association between SNS addiction test score and living context, family size or number of friends.

Among the average users 69 (50.4\%) had a close relationship with family, 50 (36.5\%) with friends and 18 (13.1\%) with their partner. Of the moderate to high risk users 35 (36.1\%) had a close relationship with family, 51 $(52.6 \%)$ with friends and 11 (11.3\%) with their partner. A statistically significant association $(p<0.04)$ was observed between friends as close relations and SNS addiction test score. Odds ratio is $0.51(95 \% \mathrm{Cl}$ of $0.30-0.87)$.

Among those who considered themselves to be addicted to SNS, 24 (43.6\%) were average users while 31 (56.4\%) were moderate to high users. Among those who thought they were not addicted to SNS 11 (67.6\%) were average users and $53(32.3 \%)$ were moderate to high users and a statistically significant association $(p<0.002)$ was observed between self-assessment of addiction to SNS and SNS addiction test score.

\section{Discussion:}

\section{Use of social networking sites}

This study aimed to assess the frequency of social networking sites usage and evaluate the potential for SNS addiction among university students. Most of the participants were found to be users of social networking sites and Facebook was the most popular SNS. This result is similar to Ellison's study, where majority of undergraduate students were Facebook members ${ }^{15}$, and also the study among students at the University of Illinois where $88 \%$ of respondents were SNS users ${ }^{16}$. An ECAR study showed that the usage of Social networking sites in the 18-19 year old age group is at an astonishing 95\%, 20-24 it's at $92.8 \%$ and above the age of $30,37 \%$. It also states that its prevalence among all students (college and university) is $85 \%$. The daily use of SNS has risen from $32 \%$ in $2006-49 \%$ in $2007-52 \%$ in $2008^{10}$.

On analyzing demographic characteristics of users and nonusers, it was found that gender was not a significant factor affecting SNS use which is similar to the findings of the ECAR study $^{10}$. The latter study also concluded that age was a powerful contributing factor and found the frequency of usage to be highest in the college going age group. However our study population comprised only of university students with a mean age of 21 years and we did not find any difference in SNS use within these narrow age groups. More number of junior students i.e. those in their first and second years of study used SNS more frequently. This may also be associated with the probably reduced academic workload in the initial years of university. Majority of non-users were from a larger family.

\section{Addictive use of Social Networking sites}

Using the SNS addiction test score, $58.8 \%$ of the study 
population were average users, $37.8 \%$ moderate and $3.4 \%$ were high users. The last group is the one with highest potential for SNS addiction and in need of further assessment and intervention. Considering the fact that SNS use is another component of internet usage, this is high when compared to the internet addiction found in other studies $6,{ }^{17}$. In the Illinois study, $74 \%$ of SNS users reported use of at least one site often2. The daily use of SNS is reported to have risen from $32 \%$ in $2006-49 \%$ in $2007-52 \%$ in $2008^{10}$.

Significant association was found between gender and addiction scores. Males were found to be more likely to be moderate to high users than females. This result is consistent with the findings of Lawrence ${ }^{18}$ and C. Frangos that males were found to have $50 \%$ increased chance of developing internet addiction ${ }^{12}$.

Among the participants aged $<20$ years, a half of them were moderate to high users when compared to those aged $>20$ years. These results are consistent with the ECAR study 10 which found higher usage in the $<20$ years age group. This is probably because they are in the initial years of university probably experiencing reduced academic workload.

There is a trend that Arab students are more likely to be moderate to high users (50.7\%). Medical students are less likely to be excessive SNS users than non-medical students probably due to greater demand on time and effort. Junior year students had a significantly greater tendency for moderate to high use than senior year students, similar to the finding of internet dependency by first year students ${ }^{19}$, probably because of less pressure of studies allowing them more time to be spent on SNS.

Almost two-third of the participants live with family, and others alone or with roommates; no significant association is seen with living context and degree of SNS use, though use was most among those living alone. Previous studies ${ }^{20}$ have found that students who live at home are less likely to use Facebook than those who live on their own, which may be due to the limitations that parents put on their children's internet use. In this study, family is taken to be parents or spouse.

There is no association seen between family size and degree of SNS use as in internet addiction ${ }^{21}$, or the number of close friends. We also found a significant association with close relations and the extent of SNS use. The majority of the moderate to high SNS users identified friends as the ones with whom they would share their joys and sorrows and were so more likely to use SNS to keep in touch.

An unexpected finding was that stress in studies and stress in personal relationships are not significantly associated with extent of SNS use in contrast with another study which associated stress-related variables with internet addiction among adolescents ${ }^{12}$.

It was found that $40 \%$ used SNS for less than or equal to 2 hours and $60 \%$ used SNS for greater than or equal to 3 hours. These results are similar to Morahan-Martin's study that showed that internet dependants are more likely to spend time on the internet than non dependants ${ }^{22}$.

With regard to the purpose of using SNS, a positive association was observed between meeting new people on
SNS and SNS addiction score test; $38.2 \%$ of the moderate to high users and $21.2 \%$ of the average users used SNS for this purpose. This is consistent with previous findings that extroverted personalities have a higher level of both SNS usage and addictive tendencies ${ }^{23}$.

It was found that there was no association between locations of access to SNS with the extent of SNS use. With regard to the universities in Ajman, most students have access to social networking sites at university, so this may increase the likelihood of use. So this is unlike the situation where Hargittai hypothesized fewer opportunities to explore social network sites with sharing of machines at home ${ }^{20}$.

\section{Conclusion:}

Being in the junior years of study and small family size were found to be associated with higher SNS use. Age less than 20 years, male gender, non-medical study program, friends as close relationship, and self perception of addiction to SNS were found to be associated with the extent of SNS use.

\section{Limitation of the study:}

A non- probability convenience sampling method was used. The students who were available in class when the questionnaires were distributed formed the participants in the study.

The standardized scores given by the Internet Addiction Test could not be extrapolated to SNS usage. The new scoring system that was devised has statistic rationale but does not have a psychometric validity.

\section{Future scope of study:}

Future studies are required to devise a standardized score for evaluation of SNS usage, and investigate the risks of excessive SNS use and addictive potential for providing appropriate education. While previous studies were regarding internet usage and addiction, the present study identified the subgroups of university students in the study area likely to overuse or be addicted to SNS. The results point to the need for further studies to establish these, overcoming the limitations of the present study.

\section{Acknowledgments}

The authors are thankful to the authorities of the institutions and the participants who made it possible to conduct the study, and for the secretarial assistance from the Department of Community Medicine and the Research Division, Gulf Medical University.

\section{Authors contributions}

GK, $A A, A B, S S$ and $M R$ have done the Literature search, Design and planned the Concepts of the study. Acquisition of the data was done by GK, AA, AB and SS. Data and Statistical analysis was undertaken by JS. EM and RBS have done the Questionnaire and Manuscript editing. 
Manuscript review was done by SAS. All the authors read and approved the final manuscript.

\section{Conflict of Interests:}

The authors do not have any conflict of interest arising from the study.

\section{What this study adds:}

By means of this study one is expected to obtain information concerning extent and purpose of use of social networking sites by university students. The researchers attempted to develop a test to detect addiction to social networking.

\section{References:}

1. Boyd DM, Ellison NB. Social Network Sites: Definition, History, Scholarship. J Comput Mediat Commun 2008;13:210-230. doi: 10.1111/j.1083-6101.2007.00393.x

2. Ellison NB, Steinfield C, Lampe C. The Benefits of Facebook Friends Social Capital and College Students Use of Online Social Network Sites. J Comput Mediat Commun 2007;12:1143-1168. doi: 10.1111/j.1083-6101.2007.00367.x

3. Thatcher A, Goolam S. Development and psychometric properties of the Problematic Internet Use Questionnaire. S Afr J Psychol 2005; 35:793-809.

4. Young KS. Internet Addiction: The Emergence of a New Clinical Disorder. Cyberpsychol Behav FALL 1998;1(3):237244. doi:10.1089/cpb.1998.1.237. Available from http://newmedia.cityu.edu.hk/COM5108/readings/newdiso rder.pdf

5. Griffiths M. Internet addiction Fact or fiction? The Psychologist: Bulletin of the British Psychological Society 1999;12:246-250. Available from http://nottinghamtrent.academia.edu/MarkGriffiths/Papers /410606/Griffiths_M.D._1999_._Internet_addiction_Fact_or _fiction_The_Psychologist_Bulletin_of_the_British_Psychol ogical_Society_12_246-250

6. Lawrence $\overline{T L}$, Zi-wen $P$, Jin-cheng $M$, et al. Factors Associated with Internet Addiction among Adolescents. Cyberpsychol Behav October 2009;12(5):551-555. doi:10.1089/cpb.2009.0036

7. Kujath CL. Facebook and MySpace: complement or substitute for face-to-face interaction? Cyberpsychol Behav Soc Netw 2011;14(1-2):75-8.

8. Huang $H$, Leung L. Instant Messaging Addiction among Teenagers in China: Shyness, Alienation, and Academic Performance Decrement. Cyberpsychol Behav 2009;12(6): 675-679. doi:10.1089/cpb.2009.0060.

9. Kandell JJ. Internet Addiction on Campus: The Vulnerability of College Students. Cyberpsychol Behav Spring 1998;1(1):11-17.doi:10.1089/cpb.1998.1.11.

10. Wise K, Alhabash S, Park H. Emotional Responses During Social Information Seeking on Facebook. Cyberpsychol Behav Soc Netw October 2010;13(5):555-562. doi:10.1089/cyber.2009.0365.

11. Widyanto L, McMurran M. The psychometric properties of the internet addiction test. Cyberpsychol Behav August
2004;7(4): 443-450. doi:10.1089/cpb.2004.7.443.

12. Christos CF, Constantinos CF, loannis S. Problematic Internet Use Among Greek University Students: An Ordinal Logistic Regression with Risk Factors of Negative Psychological Beliefs, Pornographic Sites, and Online Games. Cyberpsychol Behav Soc Netw January/February 2011;14(1-2):51-58. doi:10.1089/cyber.2009.0306.

13. Sathian B, Sreedharan J, Baboo NS, Sharan K, Abhilash ES, Rajesh E. Relevance of Sample Size Determination in Medical Research. Nepal Journal of Epidemiology 2010, 1(1):4-10.

14. Sathian B. Reporting dichotomous data using Logistic Regression in Medical Research: The scenario in developing countries. Nepal Journal of Epidemiology 2011, 1(4):111113.

15. Ellison NB, Steinfield C, Lampe C. The Benefits of Facebook Friends Social Capital and College Students Use of Online Social Network Sites. J Comput Mediat Commun 2007;12:1143-1168. doi: 10.1111/j.1083-6101.2007.00367.x 16. Hargittai E. Whose Space? Differences Among Users and Non-Users of Social Network Sites. J Comput Mediat Commun 2008;13:276-297. doi: 10.1111/j.10836101.2007.00396.x

17. Anderson K J. Internet use among college students: An exploratory study. $1998 . \quad$ Available at: http://www.rpi.edu/ anderk4.research.html.

18. Lawrence T.L, Zi-wen $P$, Jin-cheng $M$, Jin J. Factors Associated with Internet Addiction among Adolescents. Cyberpsychol Behav October 2009;12(5):551-555. doi:10.1089/cpb.2009.0036

19. Kubey RW, Lavin MJ, Barrows JR. Internet use and collegiate academic performance decrements: Early findings. Journal of Communication 2001;5:366-382.

20. Hargittai E. Whose Space? Differences among Users and Non-Users of Social Network Sites. J Comput Mediat Commun 2008;13:276-297. doi: 10.1111/j.10836101.2007.00396.x

21. Yen JY, Yen CF, Chen CC, et al. Family factors of internet addiction and substance use experience in Taiwanese adolescents. Cyberpsychol Behav 2007;10(3):323-9. doi:10.1089/cpb.2006.9948

22. Morahan MJ, Schumacher P. Incidents and correlates of pathological internet use among college students. Computers in Human Behavior 2000;16:13-29.

23. Kathryn W, Stephanie F, Katherine MW. Psychological Predictors of Young Adults' Use of Social Networking Sites. Cyberpsychol Behav Soc Netw 2010;13(2):173-177. doi:10.1089/cyber.2009.0094

\begin{tabular}{|l|l|}
\hline \multicolumn{2}{|c|}{ Article Information } \\
\hline \multicolumn{2}{|c|}{ Article history } \\
\hline Received & 21 September 2012 \\
Received in revised form & 22 March 2013 \\
Accepted & 24 March 2013 \\
\hline
\end{tabular}

